Revue des patrimoines

$21 \mid 2013$

De l'art de bâtir aux champs à la ferme moderne

\title{
De la systématisation de Bucarest à la destruction des villages roumains
}

\author{
Bogdan Andrei Fezi
}

\section{(2) OpenEdition}

Journals

Édition électronique

URL : http://journals.openedition.org/insitu/10390

DOI : $10.4000 /$ insitu. 10390

ISSN : 1630-7305

Éditeur

Ministère de la culture

Référence électronique

Bogdan Andrei Fezi, « De la systématisation de Bucarest à la destruction des villages roumains », In Situ [En ligne], 21 | 2013, mis en ligne le 11 juillet 2013, consulté le 19 avril 2019. URL : http:// journals.openedition.org/insitu/10390 ; DOI : 10.4000/insitu.10390

Ce document a été généré automatiquement le 19 avril 2019

\section{(c) $($ i) $(9)$}

In Situ Revues des patrimoines est mis à disposition selon les termes de la licence Creative Commons Attribution - Pas d'Utilisation Commerciale - Pas de Modification 4.0 International. 


\title{
De la systématisation de Bucarest à la destruction des villages roumains
}

\author{
Bogdan Andrei Fezi
}

Dès son arrivée au pouvoir en 1965, le dictateur communiste Nicolae Ceauşescu planifie la démolition massive des villages roumains. C'est le début de la "systématisation» communiste : la plus grande destruction européenne conçue en temps de paix.

\section{La Roumanie de l'entre-deux-guerres, pionnière européenne des recherches sur la vie rurale}

2 La création de la Roumanie moderne sous influence architecturale française, au XIX siècle $^{1}$, coïncide avec l'apparition d'un intérêt nouveau pour le style architectural national roumain ${ }^{2}$ et pour la protection du patrimoine historique rural. Deux architectes jouent un rôle important dans le développement de ce style national: le roumain Ion Mincu, diplômé de l'École des beaux-arts de Paris, et le français Émile André Lecomte du Noüy, élève de Viollet-le-Duc.

3 La naissance à Bucarest des écoles d'architecture, en 1892, et de sociologie, en 1896, conduit à la création d'une institution de sauvegarde du patrimoine rural de renommée internationale, le Musée du village roumain de Bucarest. L'expérience n'était pas nouvelle en Europe, les premiers musées en plein air destinés au folklore apparaissent en Suède à Skansen, près de Stockholm, en 1891, et en Norvège, au Norsk Folkemuseum, en 1894.

4 Les recherches roumaines portant sur la vie et l'architecture rurales avaient commencé en 1867 avec la construction du pavillon roumain à l'Exposition universelle de Paris, suivie par la création d'institutions spécialisées, comme le musée d'Ethnographie, d'Art national, d'Art décoratif et d'Art industriel de Bucarest, fondé en 1906 par Alexandru Tzigara-Samurca. Ces initiatives seront poursuivies sous la coordination du professeur Dimitrie Gusti, fondateur de l'École sociologique de Bucarest. À partir de 1925, il organise des campagnes de recherches interdisciplinaires en Roumanie, associant sociologues, 
ethnologues, géographes, architectes, dont les résultats immédiats sont des exposés présentés dans la capitale. Le fruit de ces recherches apporte une nouvelle vision sur les musées en plein air existants, car les exemples nord-européens étaient jugés trop romantiques, pas assez scientifiques dans leur approche de l'architecture rurale.

L'inauguration par le roi Carol II du musée du Village roumain à Bucarest, le 10 mai 1936, marque l'aboutissement de cette enquête. Des équipes de spécialistes dirigées par les professeurs Dimitrie Gusti, Henri H. Stahl ou Victor Ion Popa achètent des bâtiments ruraux appartenant aux villages étudiés (maisons, églises, installations techniques) et des objets mobiliers (fig. $\mathbf{n}^{\circ} \mathbf{1}$ ). La reconstruction de ces bâtiments est conforme aux critères d'authenticité et au respect des traditions locales de construction. Elle est accomplie par des artisans des villages dont ces constructions sont originaires et réalisée sous la surveillance des experts. Dans sa phase initiale, entre 1936 et 1940, le musée couvre une surface de 6,5 hectares, avec 33 bâtiments et annexes authentiques transférés. Leur disposition suit un plan qui reproduit la carte de la Roumanie, regroupant les édifices de l'architecture populaire selon la proximité géographique des villages d'origine, par zones représentant les principales provinces historiques du pays.

Figure 1

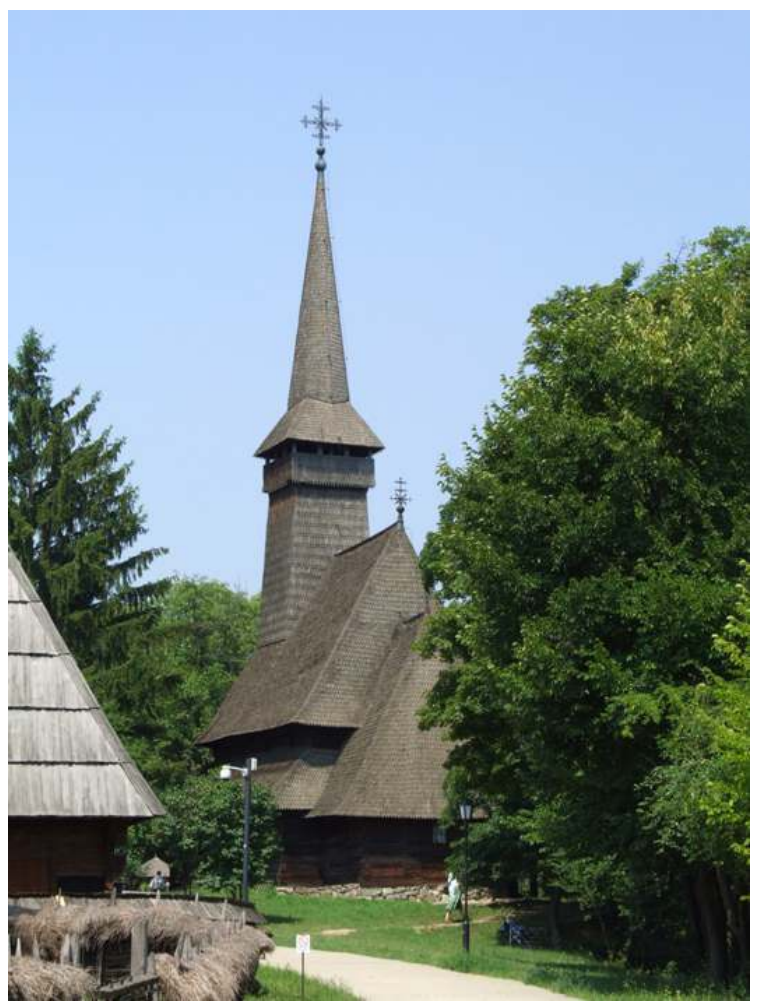

Musée du Village roumain, église reconstruite de Dragomireşti. Phot. Szala, Marcin. (c) Creative Commons, 2009.

Après une période d'intense progrès industriel et culturel, le début du $\mathrm{XX}^{\mathrm{e}}$ siècle trouve l'ensemble de la Roumanie en phase avec les puissances européennes. La capitale, Bucarest, où les premières percées «haussmanniennes » datent de 1865 , suivies d'une longue série de travaux urbains, commence à devancer d'autres villes européennes de cette époque, où les grands travaux haussmanniens tardent à apparaître, comme à Bruxelles, entre 1867 et 1871, Prague après 1893 ou Madrid après 1904. L'entrée de 
Bucarest dans le concert européen se traduit aussi par le Concours international d'urbanisme de 1906, en avance sur ceux des principales capitales européennes: le concours pour le Grand Berlin date de 1908, Paris lance son concours en 1919 et Milan en 1927. Les travaux bucarestois sont récompensés en 1939, lors de l'Exposition internationale de l'eau à Liège, recevant une médaille d'or pour les ouvrages hydrauliques et le Grand Prix d'urbanisme pour la ville.

7 Les travaux sur la ville de Bucarest et les avancées scientifiques sur la culture rurale roumaine sont reconnus au plus haut niveau mondial pendant l'entre-deux-guerres. En 1934, le rapport du vice-président allemand $\mathrm{K}$. Jeserich à la Conférence préliminaire de l'Union internationale des villes et des autorités locales mentionne qu'« à coté de la France il faut citer la Roumanie, le seul pays européen qui tente de mettre en place une vraie science communale. Le droit communal est enseigné à la faculté de droit, il existe aussi l'Institut urbanistique de Bucarest qui réalise des études de science communale et qui publie la revue L'Urbanisme. [...] » Deux années avant la fondation du musée du Village roumain de Bucarest, les recherches préliminaires entreprises sont déjà mondialement reconnues: «Comme la sociologie rurale a été longtemps négligée en Europe, les travaux de l'Institut des sciences sociales fondé par le professeur Dimitrie Gusti méritent une appréciation spéciale ${ }^{3}$ »

\section{La collectivisation du début du communisme}

8 À la fin de la Seconde Guerre mondiale, la Roumanie est occupée par les troupes soviétiques pendant quatorze ans. Les élections falsifiées de 1946 amènent les communistes au pouvoir jusqu'en 1989 et ouvrent le chemin à la nationalisation des biens privés, la suppression des partis politiques, l'abolition de la liberté d'expression accompagnée d'une répression sanglante de type stalinien.

9 Le premier « assaut » lancé sur le village roumain est la collectivisation. Commencée en Union soviétique par Staline, en 1929, elle vise à la suppression de la propriété paysanne individuelle des terrains et du marché agricole libre. En Roumanie, elle se met en place entre 1949 et 1962, années où la "transformation socialiste de l'agriculture » est officiellement accomplie ${ }^{4}$.

10 Les paysans roumains s'y opposent. La « transformation socialiste de l'agriculture » est un échec pour les communistes roumains, les paysans n'en reçoivent aucun bénéfice économique. Les procédés des autorités sont atroces: déportations, emprisonnements, destructions du système traditionnel de propriété. En 1949, les révoltes paysannes atteignent leur apogée dans des dizaines de communes. La répression est sanglante : on ouvre le feu sur les paysans ou on les exécute. Les statistiques officielles de la Securitate montrent que, entre 1950 et 1954 seulement, 4865 paysans sont déportés dans des colonies de travail forcé et, sur 11526 personnes assignées à résidence, 1643 sont des paysans. Les dimensions du «goulag» roumain parlent d'elles-mêmes. En 1954, une année après la mort de Staline et après la fermeture des 14 camps du canal Danube-mer Noire, 22 colonies de travail, 65 prisons et 11 colonies pour les mineurs existaient toujours en Roumanie. Les détenus politiques proviennent de toutes les catégories sociales, intellectuels, hommes politiques, militaires, ouvriers, paysans. Le nombre des victimes est estimé entre 600000 et 2000000 personnes $^{5}$. 
11 La collectivisation ne produit pas une modification profonde des villages mais anéantit toute capacité de résistance aux destructions ultérieures.

\section{La « systématisation » des villages : les premières campagnes}

Entre 1949 et 1962, les premières mesures de « systématisation » communiste des villages sont prises après la confiscation des propriétés agricoles privées et leur regroupement dans des fermes appartenant à l'État. Aux répressions violentes et aux arrestations succèdent les déportations dans les nouvelles «communes spéciales ». Dans les villages on construit de nouveaux « complexes politico-administratifs » selon des plans types.

Lors de l'arrivée de Nicolae Ceauşescu au pouvoir, une grande partie de l'architecture des villages est pourtant encore intacte. La «systématisation » du pays deviendra son grand projet, relancé chaque fois qu'il s'attribuera une nouvelle fonction politique. Les premières démarches de Ceauşescu concernant les villages apparaissent en novembre 1965, quatre mois après son arrivée à la tête du pays en tant que secrétaire général du Parti communiste roumain avec la création de la Commission centrale pour la systématisation des villages (fig. $\left.\mathbf{n}^{\circ} \mathbf{2}\right)$.

Figure 2

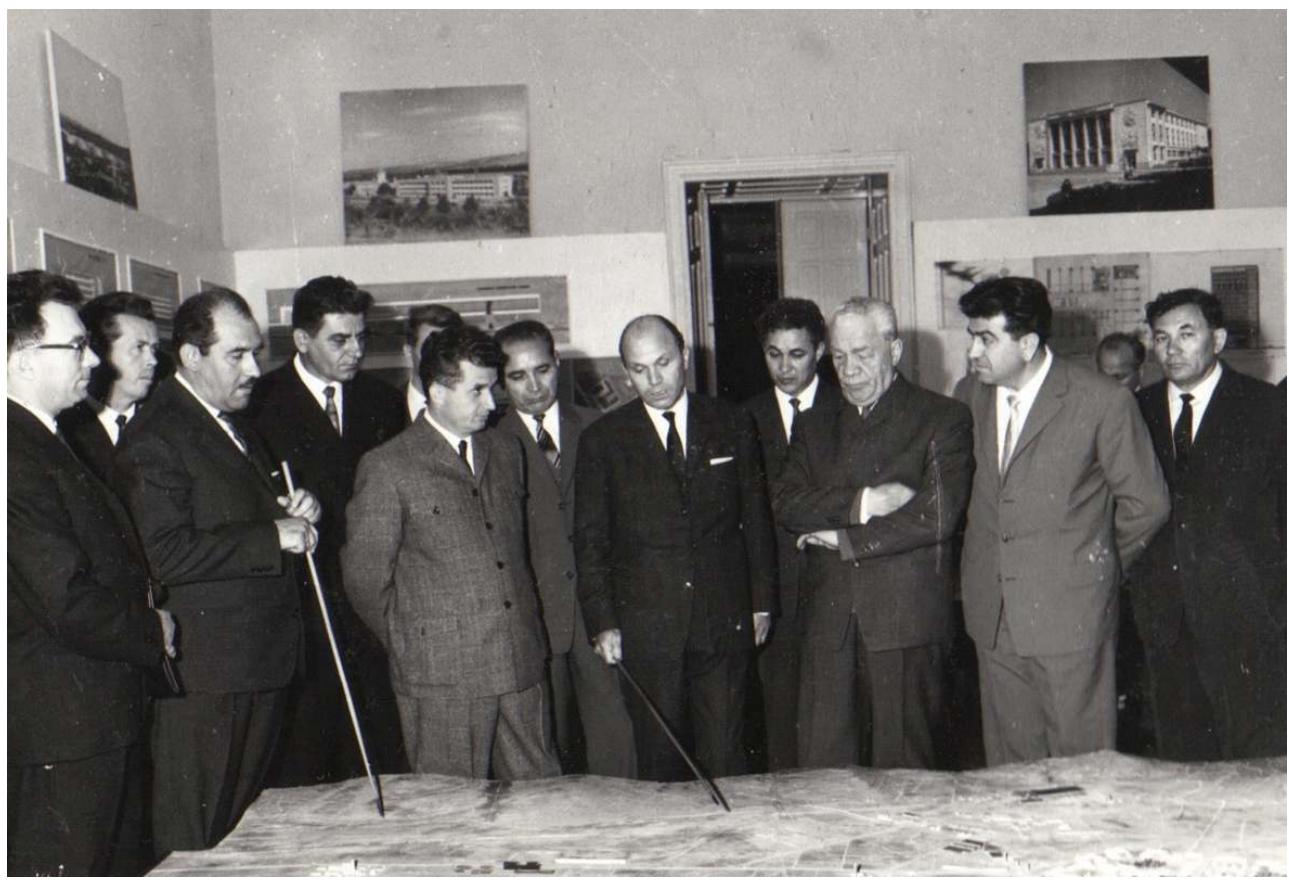

Nicolae Ceauşescu visite les projets de systématisation.

(c) Fototeca online a comunismului românesc, nº \#A145, cote 97/1966.

La seconde étape de la campagne de systématisation lancée par Ceauşescu débute avec la Conférence nationale du Parti communiste roumain de décembre 1967, où il est élu Président du Conseil d'État. À cette occasion, le parti adopte les propositions faites par le Comité central du parti et de l'État pour l'organisation des départements et des nouvelles municipalités. C'est le résultat de deux années de recherches politiques menées par les 
comités régionaux du parti unique. Les recherches scientifiques réalisées par des spécialistes de différents domaines, architectes, urbanistes, économistes, géographes, sociologues, ethnologues, sont toujours dirigées par le parti. Le nombre des départements roumains sera augmenté, leur surface moyenne réduite en fonction de différents facteurs: situation naturelle et géographique, voies de communication et liens historiques entre les localités à travers le département. On établit ainsi des unités territoriales complexes pour un « développement multilatéral et harmonieux ».

Des études pluridisciplinaires sont aussi à l'origine des propositions présentées par Ceauşescu lors de la même conférence, concernant les futures implantations rurales. Elles se fondent sur des calculs scientifiques portant sur la baisse du nombre de personnes employées dans l'agriculture, la densité plus élevée des constructions, et l'augmentation des surfaces réservées à la production agricole. En 1973, ce programme est lancé dans les départements proches de la capitale (Ilfov, Călărași), puis étendu à l'ensemble du pays. Plusieurs centaines de communes sélectionnées à travers le pays doivent être converties en centres agro-industriels et recevoir le statut de ville. Les habitants seront relogés dans des immeubles de plusieurs étages.

$\mathrm{Au}$ tournant des années 1960 et 1970, le dictateur est au sommet de sa gloire internationale, due en grande partie à sa dissidence au sein du bloc des pays communistes, après le refus de la Roumanie d'envahir la Tchécoslovaquie, en août 1968, avec les troupes du pacte de Varsovie. Il est accueilli à l'étranger avec tous les honneurs et il reçoit en Roumanie le président américain Richard Nixon, la reine Élisabeth II, le président français Charles de Gaulle et le roi d’Espagne Juan Carlos (fig. $\mathbf{n}^{\circ} \mathbf{3}$ ).

Figure 3

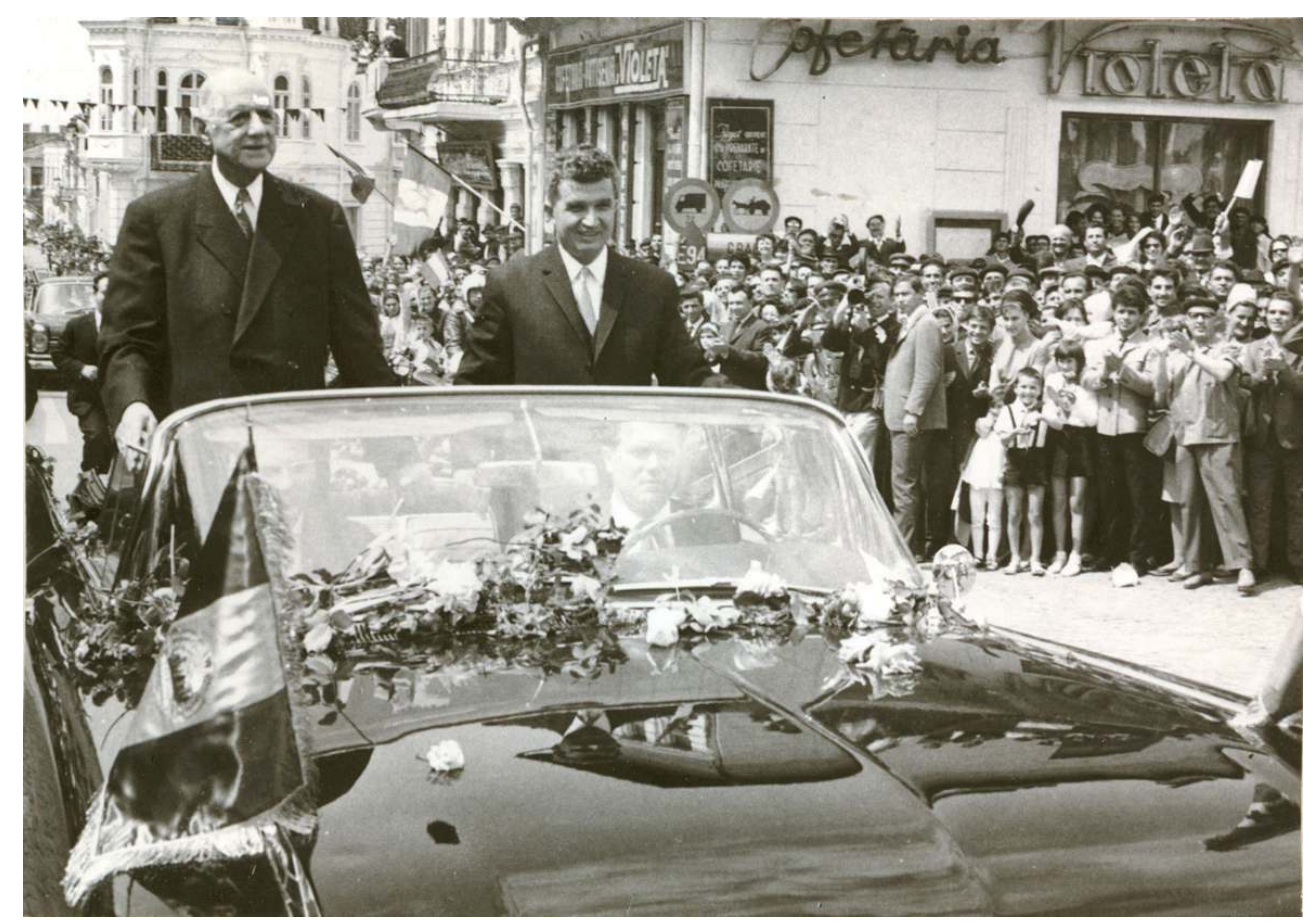

Charles de Gaulle en visite en Roumanie, 17 mai 1968.

(c) Fototeca online a comunismului românesc, n \#G457, cote 120/1966. 
17 En avril 1974, faisant toujours partie du camp soviétique mais soutenu par les Occidentaux, Ceauşescu est élu à la fonction nouvellement créée de président de la Roumanie. Il remplace ensuite le chef du gouvernement et occupe toutes les fonctions à la tête de l'État : c'est le début d'une forte dictature. La même année est promulguée la « loi $\mathrm{n}^{\circ} 58$ sur la systématisation du territoire et des localités urbaines et rurales ». Le texte de la loi prévoit un avenir urbain apparemment généreux : «La croissance sans cesse du bien-être matériel et spirituel de tous les travailleurs et l'organisation sur des bases scientifiques, de manière rationnelle et harmonieuse, du cadre où vivent et travaillent les citoyens de notre patrie. » L'objectif de «réduction du périmètre bâti des localités » semble, de nos jours, d'une grande actualité et le « rapprochement graduel des conditions de vie des villages, de celles des villes » apparaitrait comme un objectif civilisateur si l'on ne connaissait pas la farce que représenta la mise en œuvre de ces idées. La systématisation est censée être un processus démocratique, d'autant plus que les « esquisses de systématisation des communes et des villages concernés seront débattues avec les citoyens et soumises à leur vote direct ». Les conseils communaux sont même « obligés de mettre à la disposition des citoyens des projets types ». La tromperie n'est destinée qu'aux quelques Occidentaux mal informés sur le goulag roumain et sur la répression qui anéantissait toute expression contraire au parti unique.

La loi de 1974 prévoit aussi quelques détails qui gâchent les bonnes intentions affichées. Le droit de propriété est bafoué car les terrains urbains ou ruraux ne peuvent être vendus mais, mis à part l'héritage, passent automatiquement dans la propriété de l'État. La « cause d'utilité publique » du droit européen est étendue à un système de préemption pesant sur toutes les transactions. On prépare aussi les déplacements forcés de populations « des villages où la construction des nouveaux bâtiments est interdite » et le groupement dans les villages «avec perspectives de développement». Avec les déplacements de population, reprend la série d'abus et d'arrestations de la période stalinienne des années 1950. Les villes sont à leur tour confrontées à un afflux massif de population rurale difficile à absorber. Quant à l'architecture traditionnelle, elle est vouée à la disparition par la « transformation des villages dans les 15 à 20 ans à venir, en centres économiques et sociaux au caractère urbain ». Les citoyens seront ainsi mieux contrôlés par la Securitate car les différentes fonctions du bâti « doivent être groupées dans une seule construction ou dans un nombre réduit de constructions ».

\section{Bucarest rasé : le grand test des démolitions massives}

Un événement majeur mène Ceauşescu à repousser ses plans pour les villages. Le grand tremblement de terre de 1977, d'une magnitude de 7,2 degrés sur l'échelle de Richter, fait 1570 morts dont 1391 à Bucarest. La capitale compte le plus grand nombre de bâtiments affectés : 33 immeubles sont complétement détruits. Ceauşescu décrète l'état d'urgence dans tout le pays.

Ce cataclysme naturel donne au dictateur une nouvelle idée : pourquoi ne pas tout raser? Au cours d'une réunion, le 30 mars 1977, Ceauşescu expose ce vœu : "Si on démolissait Bucarest [en] entier ce serait beau ${ }^{6}$. » Le rêve digne de Néron apparaît difficile à mettre en place car le nombre de bâtiments complétement insalubres est « insuffisant ». Une année plus tard commence pourtant le projet pharaonique de Ceauşescu, le nouveau Centre civique de Bucarest. Entre 1980 et 1988 on démolit sur environ 500 hectares l'équivalent 
de presque quatre arrondissements parisiens (fig. $\left.\mathbf{n}^{\circ} \mathbf{4}\right)$. Les destructions dépassent celles dues à la Seconde Guerre mondiale et au tremblement de terre de 1977 réunis. Une bonne partie des bâtiments fait partie de l'héritage historique de la ville, dont le grand complexe du monastère Văcăreşti, l'hôpital Brâncovenesc, les Archives nationales, le marché Unirii. On démolit 40000 bâtiments $^{7}$ dont 27 églises orthodoxes, six synagogues et trois églises protestantes ${ }^{8}$. Pour les propriétaires dont les bâtiments sont démolis il n'y a pas de choix ou de recours en justice possible. Le processus d'évacuation et de démolition peut durer quelques jours seulement. L'ancien propriétaire doit déménager dans un appartement de l'État, devenant locataire. Le nouvel espace attribué ne tient pas compte de la surface démolie.

Figure 4

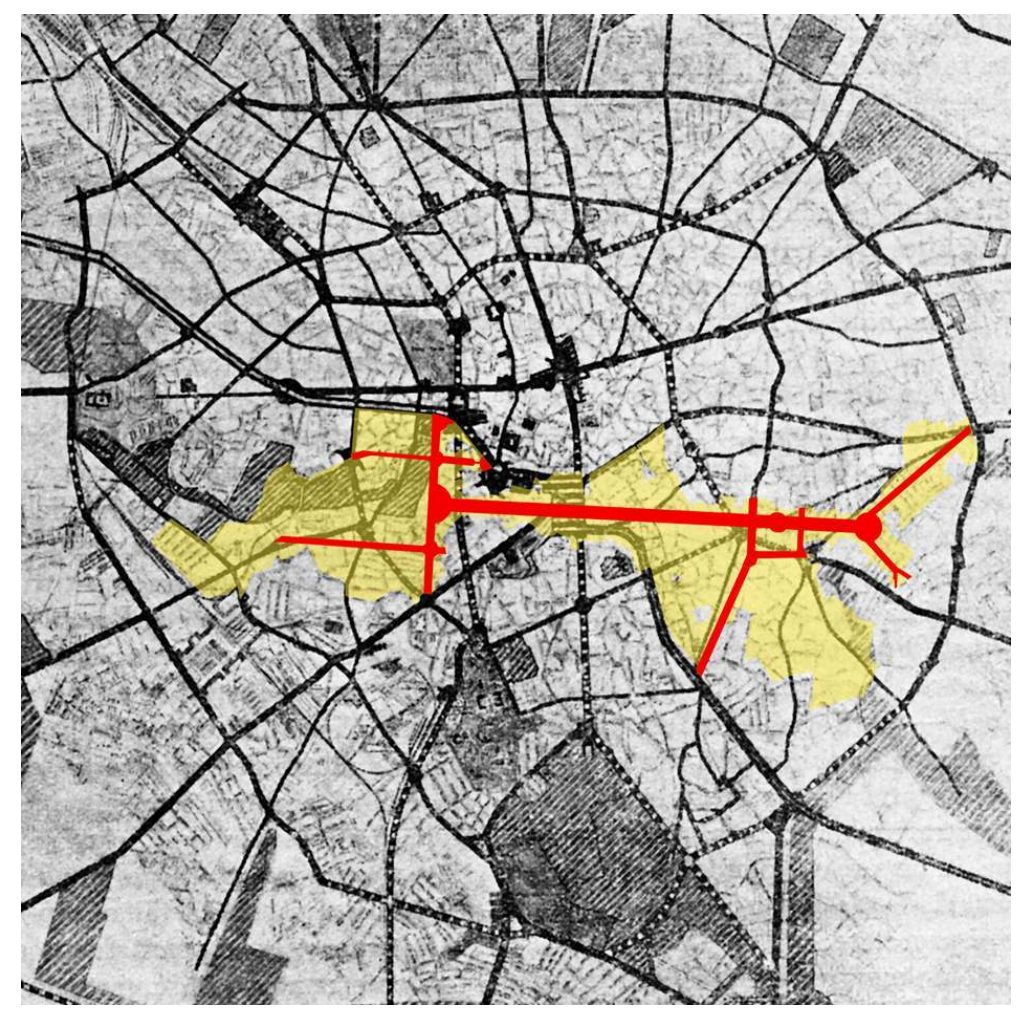

Les démolitions pour le Centre civique de Bucarest, en jaune. En rouge, le boulevard « La Victoire du socialisme ».

Dessin Fezi, Bogdan Andrei, 2010. (c) Bogdan Andrei Fezi.

Dans le nouveau Centre civique trône la maison du Peuple. Malgré l'opposition de certains architectes et historiens ainsi que de la population déplacée, 20000 ouvriers travaillent à la construction d'un bâtiment de 340000 mètres carrés et de 2550000 mètres cubes, le plus grand bâtiment administratif au monde après le Pentagone américain.

La voie est désormais ouverte à Ceauşescu pour reconstruire les villages communistes.

\section{Le nouveau projet pour les villages : la tabula rasa}

Après le grand tremblement de terre de 1977, Ceauşescu saisit le moment pour réorganiser les villages selon les principes énoncés en 1974. Il propose pour les villages 
touchés par le séisme "s'ils sont en grande partie détruits, de les concentrer sur le périmètre systématisé et de les reconstruire complétement. Je pense que nous devrions nous proposer ainsi en deux ans d'avoir cinq à six villages complétement reconstruits sous une forme qui sera aussi un modèle de l'organisation selon un projet unique ${ }^{9} »$. Les villages sont pourtant moins affectés par le tremblement de terre et, dans les années qui suivent, le dictateur se concentre sur Bucarest.

Les campagnes ont dû attendre jusqu'à l'effrayant rapport de la Section d'organisation du Comité Central du Parti communiste de 1986. Le texte prévoit la "systématisation des localités basées sur des règles de dimensionnement des terrains à l'intérieur du périmètre construit ». Même si les bonnes intentions apparentes n'ont pas l'air de changer, les chiffres donnent le frisson : le rapport prévoit que, sur les 13123 villages existants, seuls 9192 seront maintenus, les 3931 restants étant «proposés au démantèlement et à la relocalisation dans d'autres villes avec des perspectives plus grandes de développement économico-social». La surface des villages devait être réduite de moitié, de 625258 à 285839 hectares. Encore plus dramatique, 2139172 foyers seraient démolis. Cette étape ne représenterait qu'une première phase, car seuls cinq départements étaient au départ concernés par le rapport.

Sur les 3931 villages proposés à la démolition, quelques-uns sont effectivement rasés, surtout à proximité de Bucarest et de Giurgiu: Buda, Dimieni, Vlădiceasca, Ordoreanu, Coteni, Podul Ilfovului ${ }^{10}$. Le village natal du dictateur, Scorniceşti, devient officiellement une "ville" (fig. $\mathbf{n}^{\circ} 5$ ). Les conditions de vie dans les nouvelles localités, même décrites par la presse officielle, n'ont rien à voir avec les promesses du Parti communiste : la plupart des nouveaux appartements n'ont pas l'eau courante, pas de toilettes, pas de cuisine individuelle. La population vit mal. Des révoltes se produisent dans certains villages voués à la destruction. 
Figure 5

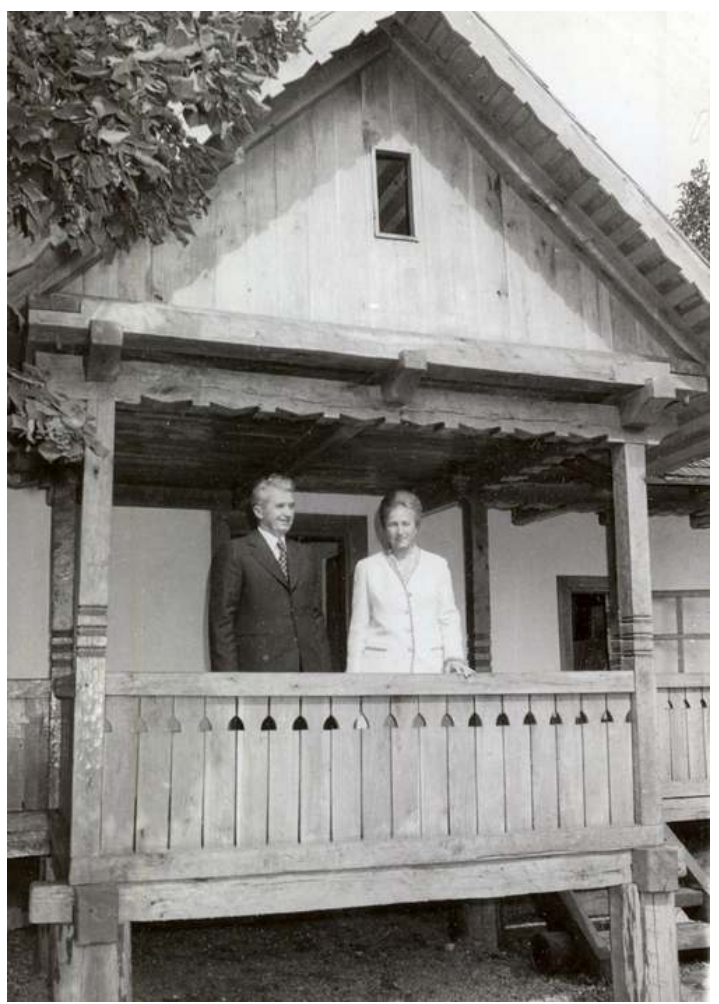

Nicolae et Elena Ceauşescu dans la maison natale de Scornicești.

(c) Fototeca online a comunismului românesc, n \#E587, cote 1/1979. 3 mars 1988 à la Conférence nationale des présidents de Conseils populaires : démolir plus de 700 communes sur 2705 et réduire le nombre des villages de 13123 à environ 5000 à 6000 seulement. Sur les villages subsistants, on prévoyait la démolition de 50 à $55 \%$ du bâti, ce qui représentait au total la disparition de $80 \%$ de la surface initiale des villages. Un véritable génocide urbain.

27 En ce qui concerne les villes, après Bucarest, d'autres agglomérations roumaines n'échappent pas à la destruction car, jusqu'en 1989, environ 29 localités sont démolies à presque $90 \%$ et reconstruites dans le style communiste.

\section{La face cachée de la systématisation des villages}

Au-delà de l'objectif affiché, le but de cette "systématisation" est le contrôle de la population. Les Roumains ont l'interdiction de passer la frontière et de se déplacer à l'intérieur du pays. Devant la pénurie de denrées alimentaires, créée par les exportations massives des années 1980, les paysans n'ont plus la main sur la production agricole qui leur assurait une modeste indépendance par rapport au régime. De plus, l'édification de bâtiments collectifs assure une surveillance plus efficace de l'omniprésente Securitate. Selon Mihnea Berindei, historien roumain exilé à Paris et activement impliqué dans la protection des villages roumains contre Ceauşescu, « ce programme vise la destruction, à terme, des dernières formes de solidarité (cellule familiale, voisinage, communauté religieuse ou nationale) qui sont considérées comme autant de foyers de résistance 
ponctuels et d'obstacles à "l'homogénéisation" de la société et à la "création d'un peuple unique ouvrier", selon les termes de Ceauşescu. Le but ultime de l'opération, clairement proclamé dans les discours officiels, est la réalisation de l'utopie totalitaire de "l'homme nouveau" - réalisation qui requiert, en dernière instance, la soumission inconditionnelle de chaque individu et sa destruction morale ${ }^{11} »$. Il s'agit de mieux contrôler la paysannerie qui garde encore une certaine indépendance économique par rapport au pouvoir. La société doit être totalement coupée du passé, des traditions. C'est la création de «l'homme nouveau».

\section{Les réactions}

29 En septembre 1988, une lettre signée par 27 Roumains, adressée à Ceauşescu, est lue à Radio Free Europe. Parmi les signataires, Doina Cornea est la plus connue en Occident car l'ancienne professeure de français avait déjà envoyé un premier texte à la chaîne de radio en 1982 alors qu'elle subissait les persécutions de la Securitate ${ }^{12}$. Les signataires, avocats, enseignants, peintres, écrivains et ouvriers, s'insurgent contre les plans de systématisation qui sont censés entraîner la démolition de milliers de villages et le regroupement des populations rurales ${ }^{13}$.

Cet appel a été le point de départ de la création de l'Opération villages roumains (OVR), par des Belges et par quelques Roumains exilés ${ }^{14}$. L'idée de base est simple : adopter des villages roumains pour les protéger. Au lancement officiel, le 3 février 1989, cinq mairies belges adoptent des villages roumains. Au mois de mars, l'OVR France s'étend à la Suisse. En décembre 1989, au moment de la chute de Ceauşescu, 2200 villages étaient déjà adoptés, dont 1252 par la France et 354 par la Belgique.

31 Les réactions des institutions étrangères se multiplient. Les projets de Ceauşescu sont condamnés par plusieurs parlements étrangers, par le Conseil de l'Europe et par l'Unesco. Le 21 février 1989, la commission politique du Parlement européen dédie sa séance au non respect des droits de l'homme en Roumanie. C'est à cette occasion qu'est lue l'émouvante lettre du dramaturge français d'origine roumaine Eugène Ionesco intitulée «Nonassistance à peuple en dange ${ }^{15} \%$. L'écrivain s'insurge contre le programme de «modernisation » des villages qui entraînera la disparition de l'habitat rural traditionnel. Eugène Ionesco lance un appel à l'Europe : «Au moment où la construction de l'Europe devient une réalité, il est un pays qui se trouve à l'heure la plus malheureuse de son histoire, au seuil de sa disparition en tant que peuple, au seuil de sa sortie définitive de l'Europe [...]. Sortir de l'Europe et sortir de l'Histoire, les deux vont de pair.» Le dramaturge fait appel à la responsabilité européenne face à la menace de disparition: "Comment ne pas réagir à ce génocide culturel dont nous sommes les témoins, comment ne pas être solidaires de ces voix qui en Roumanie ont le courage de s'élever? Ne pas les entendre, ne pas les soutenir ferait de nous des coupables de non-assistance à peuple en danger. »

Le 11 mars 1989, cinq jours après l'abolition par les soviétiques de la doctrine Brejnev d'intervention dans les pays communistes satellites, six anciens hauts dignitaires du Parti communiste roumain s'expriment publiquement à travers une lettre lue sur les antennes de Radio Free Europe et de la $\mathrm{BBC}^{16}$. Elle demande «l'arrêt du cours présent des événements avant qu'il ne soit trop tard». En outre, les signataires indiquent que "le plan entier de systématisation des villages et le déplacement forcé des paysans dans des 
immeubles de trois étages va à l'encontre de contre l'article 36 de la présente constitution qui protège le droit à la propriété privée d'un immeuble avec les annexes et le terrain sur lequel il est situé ». Enfin, ils s'insurgent contre «les mesures administratives dirigées contre les paysans. [...] Prédominante dans nos villages est maintenant la peur d'être "systématisé" avec 7000 à 8000 villages menacés d'être rasés. Au-delà de toutes les objections économiques, culturelles et humanitaires du monde civilisé sur ce programme, une question légitime apparaît : pourquoi urbaniser les villages quand vous ne pouvez pas assurer des conditions décentes de vie urbaine dans les villes?»

En 1989, la réaction de Ceauşescu est effrayante. Il prévoit une augmentation de ses objectifs : la disparition, jusqu'en 2000 , de $28 \%$ des routes, de $45,6 \%$ des réseaux de télécommunications et une réduction de $56,4 \%$ de la production électrique ${ }^{17}$. C'est le début de la déroute de Ceauşescu et de ses projets de destruction des villages roumains. La même année 1989, une grande mobilisation entraine la chute du dictateur: la destruction planifiée de plus de 8000 villages n'aura pas lieu.

\section{L'actualité des villages roumains}

Après la chute du communisme, en 1989, la question de la reconstitution de la propriété foncière après la collectivisation est devenue d'actualité : restitution des terrains aux anciens propriétaires, reconstruction des maisons individuelles, et préservation du patrimoine architectural.

Les villages roumains ont échappé aux démolitions de Bucarest mais ils risquent de tomber dans un cône d'ombre. Pour prévenir cela, l'Opération villages roumains a évolué après la chute de Ceauşescu. Les projets ont mis l'accent sur le développement durable, la création d'un réseau de tourisme rural et d'échanges d'expérience dans la sauvegarde du patrimoine rural. En 2009, l'association Opération villages roumains a fêté ses 20 ans à Bucarest. Elle fut décorée par le président roumain, ses membres invités à une série de manifestations organisées par l'Académie roumaine, l'Institut culturel roumain, le musée du Paysan roumain et l'Institut français de Bucarest ${ }^{18}$.

L'activité du musée du Village roumain, inauguré en 1936, est accompagnée par la création, en 1990, d'un nouvel établissement, le musée du Paysan roumain. L'institution poursuit l'œuvre du musée d'Ethnographie, d'Art national, d'Art décoratif et d'Art industriel de Bucarest, fondé par Alexandru Tzigara-Samurca, en 1906. L'approche muséographique hors du commun de son fondateur, le peintre Horia Bernea, lui valut, en 1996, le prix du Musée européen de l'année, accordé par le Forum européen du musée, agissant sous les auspices du Conseil de l'Europe. Reprenant ses traces d'il y a deux siècles, la Roumanie suit, à nouveau, après la chute du communisme, son chemin européen.

L'objectif poursuivi par le dictateur Ceauşescu de création de "l'homme nouveau » par la destruction de l'esprit du village traditionnel roumain n'a heureusement pas été atteint. Les relations humaines ont résisté à quatre décennies de communisme, comme a pu le constater un voyageur passionné par la Roumanie, le Prince Charles: "Ce qui est merveilleux est cette relation unique entre l'homme et son environnement. Cela manque à notre société. Les gens recherchent un certain sentiment d'appartenance, d'identité et un sens ${ }^{19}$.» 


\section{NOTES}

1. - FEZI, Bogdan Andrei. Bucarest et l'influence française. Entre modèle et archétype urbain. 1831-1921. Paris : L'Harmattan, 2005.

2. - POPESCU, Carmen. Le Style national roumain: Construire une nation à travers l'architecture, 1881-1945. Rennes : Presses Universitaires de Rennes/Simetria, 2004.

3. - Rapport du vice-président allemand $\mathrm{K}$. Jeserich présenté lors de la Conférence préliminaire de l'Union internationale des villes et des autorités locales, Lyon, juillet 1934, publié dans JESERICH, K. « ştiinţa comunală ca doctrină şi obiect de cercetare ştiinţifică în ţările civilizate » (La science communale comme doctrine et objet de recherche scientifique dans les pays civilisés). Urbanismul , janvier-février 1937, XIV (VI), nº 1-2. p. 75-76.

4. - ROMAN, Cristina. "Colectivizare" dans COURTOIS, Stéphane (coord.). Dicţionarul comunismului (Le dictionnaire du communisme). Bucarest : Polirom, 2008, p. 692.

5. - LĂCĂTUşU, Dumitru. « Sistem concentraŢionar ». Dicţionarul comunismului, p. 696.

6. - Voir le sténogramme de la séance CPEx du 10 mars 1977, dans ANIC, fond CC al PCR Cancelarie, dossier $\mathrm{n}^{\circ}$ 28/1977, f. 12-13, apud le Raportul comisiei prezidenȚiale pentru analiza dictaturii comuniste din România (Rapport final de la commission présidentielle pour l'analyse de la dictature communiste). Bucarest, 2006, p. 613.

7. - VASILESCU, Sorin. « Oraşul care a dispărut » (La ville qui a disparu). Magazin istoric, mai 1999, p. 27.

8. - MORARU, Alexandru. «Biserica românească sub dictatura comunistă » (L'église roumaine sous la dictature communiste). Studia Universitatis Babes-Bolyai - Orthodox Theology, 1989, $\mathrm{n}^{\circ} 1-2$, p. 31-40.

9. - Voir ANIC, fond CC al PCR - Cancelarie, dossier $n^{\circ}$ 20/1977, f. 15 verso et idem, dossier $n^{\circ}$ 22/1977, f. 4 r, apud Raportul comisiei prezidenȚiale pentru analiza dictaturii comuniste din România. Bucarest, 2006, p. 614.

10. - BERINDEI, Mihnea. « Operation Villages Roumains 1989 - 2005 ». Revista 22, 28 juin 2005.

11. - BERINDEI, Mihnea. « Le naufrage planifié ». Politique internationale, $\mathrm{n}^{\circ} 44$, été 1989.

12. - CORNEA, Doina. « Scrisoare către cei care nu au renunţat să gândească » (Lettre à ceux qui n'ont pas renoncé à penser). Radio Free Europe, 1982.

13. - «Roumanie: "Sacrilège." Des citoyens dénoncent le programme de systématisation du territoire de M. Ceausescu ». Le Monde, 30 septembre 1988.

14. - BERINDEI, Mihnea. «Le naufrage planifié ». Politique internationale, ${ }^{\circ} 44$, été 1989.

15. - DEBOVE, Alain. « Roumanie : les droits de l'homme devant le Parlement européen, "Nonassistance à peuple en danger", selon Eugène Ionesco ». Le Monde, 23 février 1989.

16. - Alexandru Bârlădeanu, Corneliu Mănescu, Grigore Răceanu, Constantin Pârvulescu et Silviu Brucan. Lettre lue à la Radio Free Europe et à la BBC, 11 mars 1989.

17. - BERINDEI, Mihnea. « Distrugerea satelor româneşti în arhivele Comitetului Central ». Revista 22, 30 juin 2009.

18. - PATAPIEVICI, Horia-Roman. «SENATUL EVZ: Să ne amintim de OVR » (LE SENAT EVZ: Rappelons-nous l'OVR). Evenimentul zilei, 5 mars 2009.

19. - Prince Charles, prince de Galles, interview dans Wild Carpathia, un film documentaire, coproduction Almond Films, Travel Channel et The European Nature Trust, diffusé sur Travel Channe en 2011. Le prince est un grand admirateur de la Roumanie et, depuis sa première visite, en 1993, il y voyage régulièrement et y a acheté plusieurs propriétés. 


\section{RÉSUMÉS}

Sur le terrain préparé par la collectivisation et par la répression politique soviétique en Roumanie, Ceauşescu planifie, à partir de 1965, la «systématisation» des villages. Le projet prévoyait de raser complétement un tiers des 13123 localités et, finalement, de mieux organiser le contrôle politique. Les réactions roumaines et internationales, après la prise de conscience consécutive à la démolition sauvage d'une bonne partie du centre historique de Bucarest, ont conduit à l'arrêt de ce génocide des campagnes roumaines à la veille de la chute du dictateur, en 1989.

On the field prepared by the collectivization and by the Soviet political repression in Romania, Ceausescu planned, starting from 1965, to "systematize" the Romanian villages. The project intended to demolish a third of 13,123 villages and finally to better organize the control over the population. After the savage demolitions of a large part of the historic centre of Bucharest, Romanian and international reactions against the villages "systematization" stopped this genocide of the Romanian countryside on the eve of the dictator's fall, in 1989.

\section{INDEX}

Mots-clés : Roumanie, Bucarest, village, architecture, urbanisme, communisme, collectivisation, Nicolae Ceauşescu

\section{AUTEUR}

\section{BOGDAN ANDREI FEZI}

Docteur en architecture et urbanisme de l'université Paris 8, Enseignant à l'université d'Architecture et d'Urbanisme « Ion Mincu », Bucarest bogdan.andrei.fezi@wanadoo.fr 